Check for updates

Cite this: Chem. Sci., 2018, 9, 8253

๑ All publication charges for this article have been paid for by the Royal Society of Chemistry

Received 27th July 2018

Accepted 31st August 2018

DOI: $10.1039 / \mathrm{c} 8 \mathrm{sc} 03339 \mathrm{k}$

rsc.li/chemical-science

\section{Redox-triggered cascade dearomative cyclizations enabled by hexafluoroisopropanol $\uparrow$}

\author{
Shuai-Shuai Li, (D) ${ }^{a}$ Xintong Lv, ${ }^{a}$ Didi Ren, ${ }^{a}$ Chang-Lun Shao, ${ }^{b}$ Qing Liu ${ }^{c}$ \\ and Jian Xiao (DD *a
}

An unprecedented cascade dearomative cyclization through hydrogen-bonding-assisted hydride transfer is realized. The aggregate effect of HFIP enables the rapid buildup of polycyclic amines directly from phenols and o-aminobenzaldehydes via a cascade dearomatization/rearomatization/dearomatization sequence. This unique transformation addressed the drawbacks of hydride transfer-involved redox-neutral reactions.

\section{Introduction}

The direct $\alpha-\mathrm{C}-\mathrm{H}$ functionalization of amines provides the most powerful toolbox for the synthesis of highly functionalized cyclic amines, which are increasingly momentous scaffolds in the exploration of new pharmaceuticals. ${ }^{1}$ The desire for an oxidant-free and green process has brought about the renaissance of intramolecular hydride transfer as a key step for $\alpha-\mathrm{C}-\mathrm{H}$ functionalization of amines. ${ }^{2}$ The atom-economic and redoxneutral nature of this transformation makes it ideal for sustainable and complexity-enhancing amine synthesis. However, for a long time, hydride acceptors have been dominated by electrophilic alkenes, typically activated by double electron-withdrawing groups, ${ }^{3}$ whereas the utilization of other types of hydride acceptors remains elusive (Scheme 1). ${ }^{4,5}$ So far, this type of reaction has generally relied on substrate engineering, and hydride acceptors and donors have to be installed into one substrate beforehand via synthetic operations, which are often dissimilar from the targets. Furthermore, the typical protocols necessitate strong Lewis acids or Brønsted acids for decent yields, and high temperature is demanded in most cases. These disadvantages restrict the applicability of this method for the synthesis of structurally diverse cyclic amines as well as their utility for late-stage functionalizations.

Probably, the high energy barrier for the cleavages of $\alpha-\mathrm{C}-\mathrm{H}$ bonds accounts for the current situations. ${ }^{6}$ To address these

${ }^{a}$ Shandong Province Key Laboratory of Applied Mycology, College of Chemistry and Pharmaceutical Sciences, Qingdao Agricultural University, Qingdao, 266109, China. E-mail: chemjianxiao@163.com

${ }^{b}$ Key Laboratory of Marine Drugs, The Ministry of Education of China, School of Medicine and Pharmacy, Ocean University of China, Qingdao 266003, China

${ }^{c}$ College of Chemical and Environmental Engineering, Shandong University of Science and Technology, Qingdao 266590, China

$\dagger$ Electronic supplementary information (ESI) available. CCDC 1829304. For ESI and crystallographic data in CIF or other electronic format see DOI: $10.1039 / \mathrm{c} 8 \mathrm{sc} 03339 \mathrm{k}$ challenges, we propose the use of highly reactive species, orthoquinone methides $(o$-QMs), to trigger hydride transfer reactions, offsetting the high activation energy of $\mathrm{C}-\mathrm{H}$ bond cleavages. Although $o$-QMs have been extensively used as synthetic intermediates with wide-ranging applications in constructing useful chemical structures, ${ }^{7}$ to the best of our knowledge, there is no example for the hydride transfer-involved cascade reactions of $o$-QMs. ${ }^{8}$ Moreover, all the reactions involving $o$-QMs ended up with thermodynamically stable phenol derivatives and no report was available for dearomative cyclohexaketenes as final products. ${ }^{9}$ As part of our continuing interest in one-step assembly of molecular complexity via hydride transfer reactions, ${ }^{5,10}$ herein, we report a conceptually distinct strategy that is the employment of aromatization of QMs as a driving force to initiate hydride transfer-involved cascade reactions, realizing redox-neutral cascade dearomative cyclizations with cyclohexaketene-embedded polycyclic amines as final products (Scheme 1). It is noteworthy that these architecturally complex

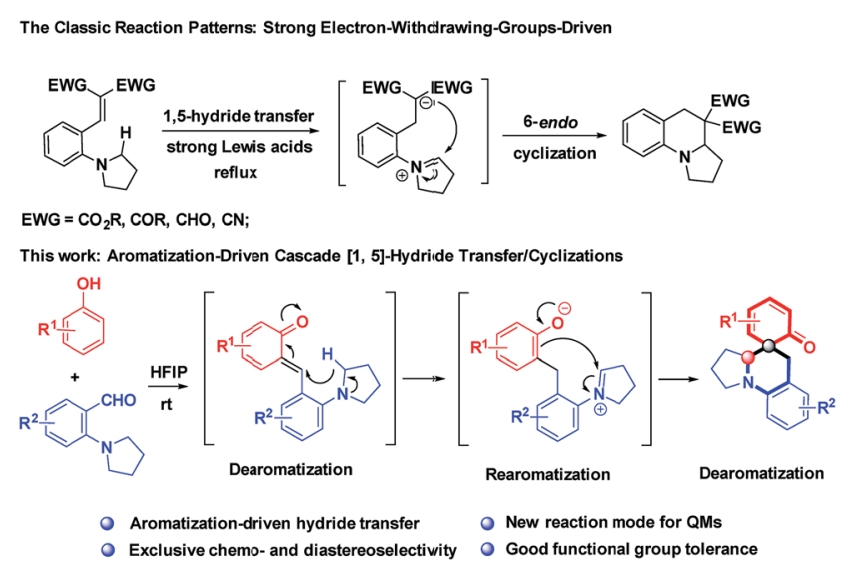

Scheme 1 Cascade dearomative cyclizations via a dearomatization/ rearomatization/dearomatization sequence. 
structures were inaccessible via a one-step reaction, despite their prevalence in a number of natural products. ${ }^{\mathbf{1 1}}$

\section{Results and discussion}

\section{Optimization of HFIP-promoted dearomatization of sesamol with aminobenzaldehyde}

Undoubtedly, the in situ generation of precursors of $o$-QMs from readily accessible starting materials would be an attractive strategy for future application of $o$-QMs-involved reactions. Thus, we embarked on our research through screening the reaction between sesamol 1a and 2-(pyrrolidin-1-yl)benzaldehyde 2a, as shown in Table 1.

Initially, $10 \mathrm{~mol} \%$ protonic acids were employed in DCE to catalyze this reaction at room temperature (entries 1-3). To our delight, the desired product 3a was obtained when BINOLderived phosphoric acid and (-)-CSA were used, albeit with low productivities (entries 1-2). Unfortunately, the strong trifluoromethanesulfonic acid (TfOH) did not produce the desired product at all. The structure of 3a was unambiguously confirmed by X-ray crystallographic analysis (see the ESI $\dagger$ ). Next, various Lewis acid catalysts were evaluated to improve the reaction efficiency (entries 4-8). It was found that only $\mathrm{InCl}_{3}$ could afford the desired product in satisfying yield after 8 days (entry 4). In view of the unique properties of fluorinated alcohols ${ }^{\mathbf{1 2}}$ and our recent success in hydrogen-bonding activation by these solvents, ${ }^{13}$ subsequently, trifluoroethanol (TFE) and hexafluoro-2-propanol (HFIP) were examined at room temperature acting as both promoters and solvents (entries 9-10). Disappointingly, the product was yielded only in $32 \%$ yield in TFE (entry 9). Nevertheless, HFIP exhibited good productivity, promoting this cascade reaction to deliver $3 \mathbf{3 a}$ in $81 \%$ yield within 12 hours (entry 10). Additionally, exclusive chemoselectivity and excellent diastereoselectivity (>20:1) were also observed. However, when $\mathrm{H}_{2} \mathrm{O}$ and a non-fluorinated alcohol such as i-PrOH were used as solvents, they did not take effect at all (entries 11-12). Further screenings with 10 mol\% HFIP in i-PrOH (entry 13) or acid catalysts in $\mathrm{MeOH}$ (entries 14-16) were unsuccessful, demonstrating that the use of HFIP as a solvent was important. This result implied that the hydrogen bonding network and the hydrogen bond donor ability of HFIP were important for the success of this reaction. With this result in hand, the reaction conditions by varying the concentrations and ratio of starting materials was further investigated. It was found that decreasing concentration was beneficial to this transformation, affording $\mathbf{3 a}$ in $88 \%$ yield (entries 17-18). However,

Table 1 Optimization of cascade dearomative cyclizations ${ }^{a}$

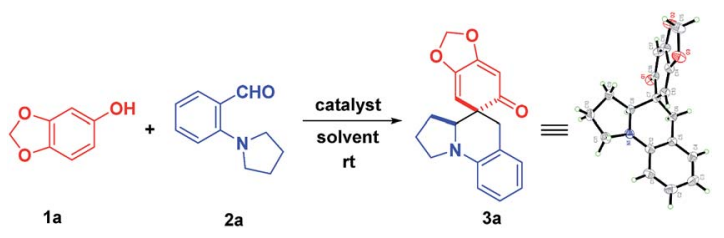

\begin{tabular}{|c|c|c|c|c|c|}
\hline Entry & Ratio (1a : 2a) & Catalyst (10 mol\%) & Solvent & Concentration $\left(\mathrm{mol} \mathrm{L}^{-1}\right)$ & Yield $^{b}(\%)$ \\
\hline $1^{c}$ & $1.3: 1$ & $(+/-)-\mathrm{PA}$ & DCE & 0.1 & 12 \\
\hline $2^{d}$ & $1.3: 1$ & $(-)-\mathrm{CSA}$ & DCE & 0.1 & 15 \\
\hline $4^{e}$ & $1.3: 1$ & $\mathrm{InCl}_{3}$ & DCE & 0.1 & 71 \\
\hline 5 & $1.3: 1$ & $\mathrm{BF}_{3} \cdot \mathrm{Et}_{2} \mathrm{O}$ & DCE & 0.1 & 0 \\
\hline $6^{e}$ & $1.3: 1$ & $\mathrm{Zn}(\mathrm{OTf})_{2}$ & DCE & 0.1 & 37 \\
\hline 9 & $1.3: 1$ & - & TFE & 0.1 & 32 \\
\hline $10^{f}$ & $1.3: 1$ & - & HFIP & 0.1 & 81 \\
\hline 11 & $1.3: 1$ & - & $\mathrm{H}_{2} \mathrm{O}$ & 0.1 & 0 \\
\hline 12 & $1.3: 1$ & - & $\mathrm{iPrOH}$ & 0.1 & 0 \\
\hline $13^{g}$ & $1.3: 1$ & HFIP & $\mathrm{iPrOH}$ & 0.1 & 0 \\
\hline 14 & $1.3: 1$ & $(-)-\mathrm{CSA}$ & $\mathrm{MeOH}$ & 0.1 & 0 \\
\hline $19^{i}$ & $1.5: 1$ & - & HFIP & 0.05 & 69 \\
\hline $20^{i}$ & $1.2: 1$ & - & HFIP & 0.05 & 86 \\
\hline $21^{i}$ & $1.1: 1$ & - & HFIP & 0.05 & 78 \\
\hline
\end{tabular}

${ }^{a}$ Reaction conditions: 1a $(0.13 \mathrm{mmol}), 2 \mathrm{a}(0.1 \mathrm{mmol})$, and $10 \mathrm{~mol} \%$ catalyst in $1.0 \mathrm{~mL}$ of solvent at room temperature under air for $48 \mathrm{~h} .{ }^{b}$ Isolated yield after column chromatography; dr $>20: 1$; dr was determined by ${ }^{1} \mathrm{H}$ NMR spectroscopy. ${ }^{c}(+/-)-\mathrm{PA}=(+/-)-1,1^{\prime}$-binaphthyl-2,2'diylhydrogenphosphate. ${ }^{d}(-)$-CSA $=(-)$-10-camphorsulfonic acid. ${ }^{e} 8$ days. ${ }^{f} 12 \mathrm{~h} .{ }^{g}$ HFIP $(0.1 \mathrm{mmol})$ for $48 \mathrm{~h} .{ }^{h} 0.5 \mathrm{~mL}$ HFIP for $12 \mathrm{~h} .{ }^{i} 2.0 \mathrm{~mL}$ HFIP for $12 \mathrm{~h}$. 
an attempt to improve the reaction efficiency through adjusting the ratio of starting materials met with failure (entries 19-21). Consequently, the most effective reaction conditions were using HFIP as both the reaction promoter and the solvent, with the ratio of $1 \mathrm{a}$ and $2 \mathrm{a}$ being $1.3: 1$.

\section{Substrate scope of HFIP-promoted cascade reactions of phenols with aminobenzaldehydes}

Under the optimized reaction conditions, the substrate scope with regard to $o$-aminobenzaldehydes 2 was firstly investigated. As shown in Scheme 2, a variety of electronically and sterically diverse substituents were installed on the aromatic ring of 2(pyrrolidin-1-yl)benzaldehydes to evaluate the generality of this methodology. To our delight, these reactions proceeded smoothly, yielding the corresponding products in moderate to good yields with high stereocontrol (>20:1 dr) in most cases. Notably, the substrates bearing either electron-deficient or electron-rich substituents at the para-position of the formyl group reacted smoothly with sesamol, affording $\mathbf{3 b} \mathbf{b} \mathbf{3} \mathbf{k}$ in good to excellent yields. Particularly, a broad range of functional groups, including boronate (3f), alkenyl (3g), cyano (3h), alkynyl

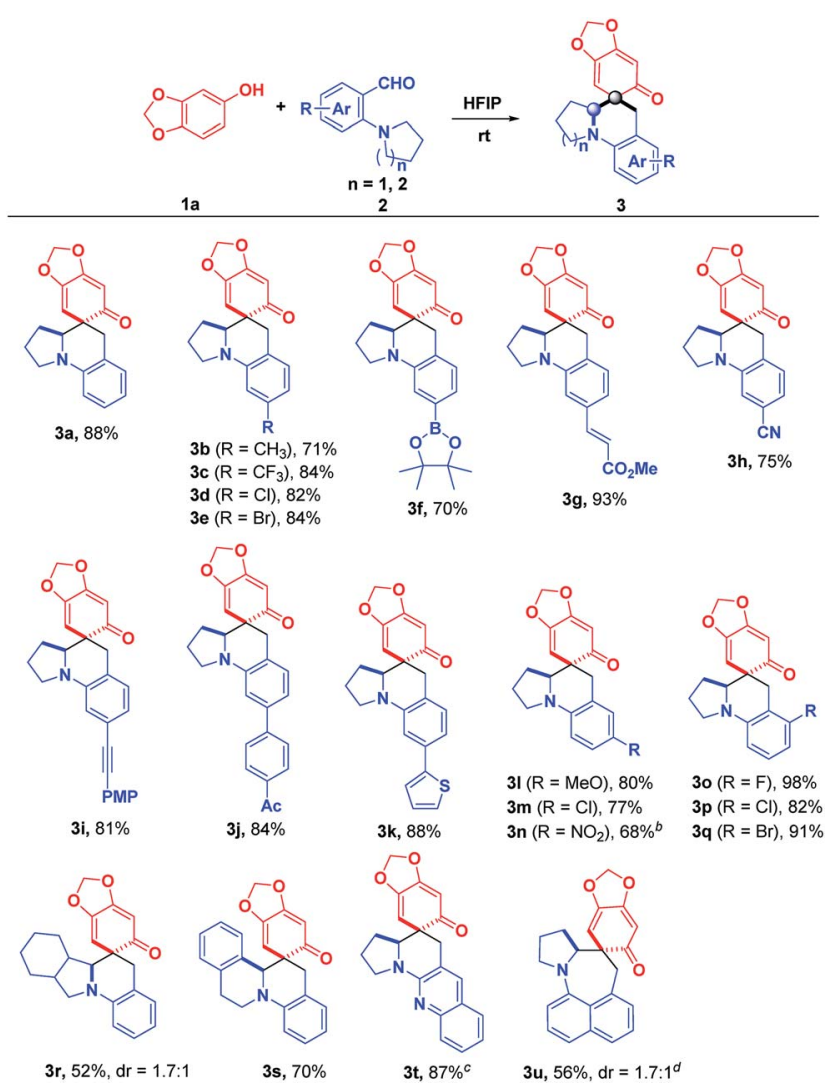

Scheme 2 Substrate scope: o-aminobenzaldehydes. ${ }^{a}$ Reaction conditions: 1a $(0.13 \mathrm{mmol})$ and $2(0.1 \mathrm{mmol})$ in $2.0 \mathrm{~mL}$ HFIP at room temperature under air; isolated yield; $d r>20: 1 ; d r$ was determined by ${ }^{1} \mathrm{H}$ NMR spectroscopy. ${ }^{\mathrm{b}}$ At $40{ }^{\circ} \mathrm{C}$. ${ }^{\mathrm{C}}$ In $1.0 \mathrm{~mL}$ toluene and $1.0 \mathrm{~mL} \mathrm{HFIP}$ at $120^{\circ} \mathrm{C}$. ${ }^{\mathrm{d}} 1 \mathrm{a}(0.13 \mathrm{mmol}), 2(0.1 \mathrm{mmol})$, and 2.0 equiv. of piperidine were added to $1.0 \mathrm{~mL}$ toluene with stirring for $12 \mathrm{~h}$ at $120{ }^{\circ} \mathrm{C}$, and then cooled to room temperature followed by the addition of $1.0 \mathrm{~mL}$ HFIP and stirred for another $10 \mathrm{~min}$. (3i), acetyl (3j) and thienyl (3k), were all well tolerated, demonstrating its robust compatibility for preparing diversely functionalized target molecules. Further investigation of the impact of the substituent positions indicated that the substituents at the meta-position of the formyl group also worked nicely, affording the corresponding products $\mathbf{3 1 - 3 n}$ in good yields. The sharp contrast between methoxyl and nitro groups illustrated that the strong electron-withdrawing substituent diminished the reactivity, which requires slightly higher reaction temperature and longer reaction time (31 and $\mathbf{3 n}$ ). Satisfyingly, the substrates 2 with substituents at the ortho-position of the formyl group were also totally compatible, furnishing the desired products $\mathbf{3 o - 3 q}$ in almost quantitative yields. Not surprisingly, a further modulation of the pyrrolidine ring was feasible, affording the privileged polycyclic products $3 \mathbf{r}$ and $3 \mathbf{s}$ in $52 \%$ and $70 \%$ yields, respectively. In addition to pyrrolidine and octahydro-isoindole rings, tetrahydroisoquinoline was also a good candidate for this reaction, giving rise to the tetrahydroisoquinoline-fused polycyclic compound $3 \mathbf{s}$ in good yield, which is a privileged moiety for medicinal chemistry. It was worth mentioning that the replacement of the phenyl skeleton by a quinoline framework was also feasible, furnishing 3t in $87 \%$ yield, albeit with higher temperature. More importantly, the cascade reaction of 1a with 8-(pyrrolidin-1-yl)-1naphthaldehyde, which involved a 1,6-hydride transfer through space, was also applicable to afford the product $3 \mathbf{u}$ in $56 \%$ yield.

Subsequently, the substrate scope of phenols and their derivatives was tested to examine the generality of the strategy (Scheme 3). Encouragingly, the phenols substituted by electrondonating groups reacted smoothly with 2-(pyrrolidin-1-yl) benzaldehyde $\mathbf{2 a}$, providing spirocyclic amines $\mathbf{3 v} \mathbf{v} \mathbf{3 z a}$ in moderate to excellent yields with exclusive chemoselectivity and excellent diastereoselectivities (>20:1 dr). Apparently, the

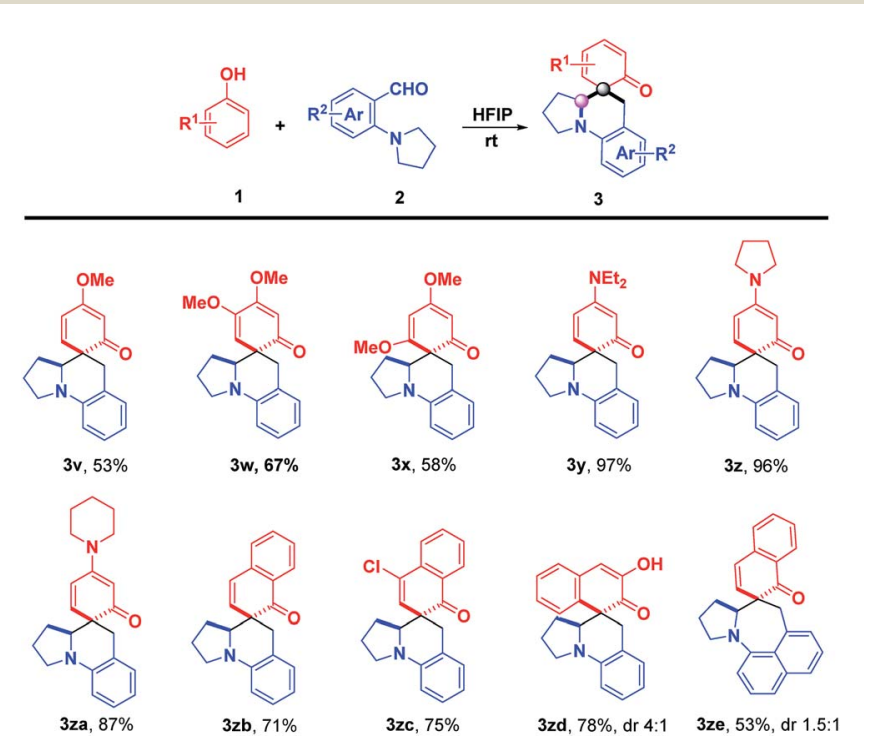

Scheme 3 Substrate scope: phenols. Reaction conditions: 1 $(0.13 \mathrm{mmol})$ and $2(0.1 \mathrm{mmol})$ in $2.0 \mathrm{~mL}$ of HFIP at room temperature under air; isolated yield; $d r>20: 1$; dr was determined by ${ }^{1} \mathrm{H}$ NMR spectroscopy. 
electronic characteristics had a significant impact on the reaction efficiency. For instance, substrates with amino groups (3y3za) led to much higher yields than methoxyl groups (3v-3x). Apart from phenols, 1-naphthols and 2,3-naphthalenediol could also be transformed into $\alpha$-spirocyclic dearomative products 3zb-3ze in good yields. Unfortunately, 2-naphthols were inert reaction partners, even under reflux temperature. In previous reports, the auxiliary side chain has to be pre-installed at the ortho-position of the hydroxyl group of phenols or naphthols to achieve dearomative 2,4-cyclohexadienone motifs. ${ }^{14}$ However, in our cases, phenols or naphthols could be directly converted to various dearomative products.

In order to further expand the universality of this strategy, 2,6-di-tert-butylphenol 4 was investigated to synthesize paraspirocyclic ketenes, aiming to solve the scope limitations of ortho-spirocyclic ketene products (Scheme 4). Gratifyingly, the desired reactions occurred smoothly, yielding the corresponding para-spirocyclic ketenes $\mathbf{5 a - 5 h}$ without an adverse effect on the efficiency. In contrast to ortho-spirocyclic ketenes, the addition of piperidine was necessary to accelerate the formation of para-quinone methides ( $p$-QMs).

\section{The synthetic elaboration of this method}

To explore the synthetic utility of this method, a gram-scale reaction between 1a and 2a was carried out in HFIP at room temperature, furnishing $3 \mathbf{a}$ in $80 \%$ yield (Scheme 5). Further structural manipulation of $\mathbf{3 a}$ is summarized in Scheme 6 . Interestingly, partially hydrogenated product $\mathbf{6 a}$ was produced under an atmosphere of $\mathrm{H}_{2}(5 \% \mathrm{Pd} / \mathrm{C})$. When Grignard reagents were subjected to the THF solution of $3 \mathbf{a}$, benzylated aniline derivatives 7 a-e were furnished in $65-82 \%$ yields, including the arylation, allylation, vinylation, alkylation, and alkynylation

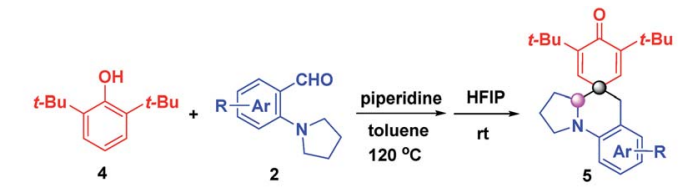

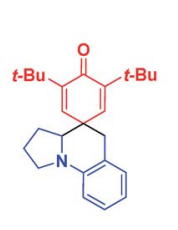

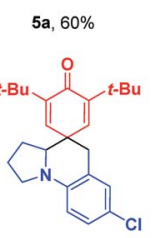

$5 e, 62 \%$

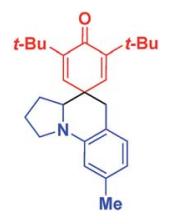

5b, $85 \%$

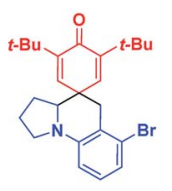

$5 f, 52 \%$

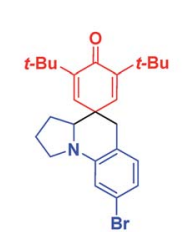

$\mathrm{Br}$

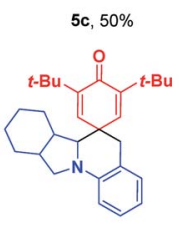

5g. $75 \%$
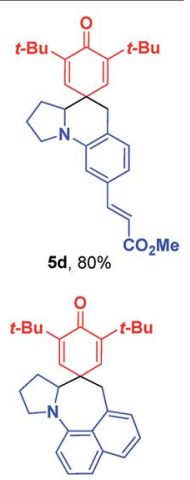

5h, $91 \%$
Scheme 4 Substrate scope for the formation of para-spirocyclic ketenes. $4(0.13 \mathrm{mmol}), 2(0.1 \mathrm{mmol})$, and piperidine (2.0 equiv.) were added to $1.0 \mathrm{~mL}$ toluene with stirring for $12 \mathrm{~h}$ at $120{ }^{\circ} \mathrm{C}$, and then cooled to room temperature followed by the addition of $1.0 \mathrm{~mL} \mathrm{HFIP}$ and stirred for another $10 \mathrm{~min}$; isolated yield.

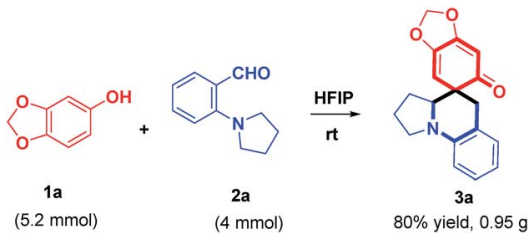

Scheme 5 Gram scale reaction.

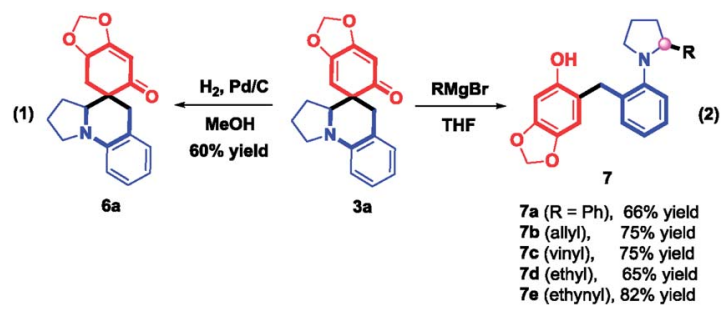

Scheme 6 Derivatization of products.

reactions, as different adducts of $\alpha-\mathrm{C}-\mathrm{H}$ functionalization of amines. The formation of $7 \mathbf{a}-\mathbf{e}$ might be attributed to the aromatization-driven sequential $\mathrm{C}-\mathrm{C}$ bond cleavage/iminium trapping, which clearly demonstrated the power of rearomatization. It should be noted that the preparation of benzylated aniline in a regioselective manner is challenging, ${ }^{15}$ considering that compound 7 is a structural hybrid between ortho-benzylated phenol and ortho-benzylated aniline motifs, which is the core structure of natural products, dyes, medicines and materials. ${ }^{\mathbf{1 6}}$

\section{Mechanistic study}

In order to probe into the mechanism of this transformation, a deuterated substrate [D]-2a was prepared and subjected to the optimal conditions (Scheme 7). The deuteration at the benzylic position of product [D]-3a fully corroborated the occurrence of intramolecular [1,5]-hydride transfer (eqn (1)). Furthermore, a deuterium kinetic isotope effect (DKIE) of 1.22 was obtained through a competitive reaction between substrate $2 \mathbf{a}$ and [D]-2a, implying that an intramolecular [1,5]-hydride transfer might

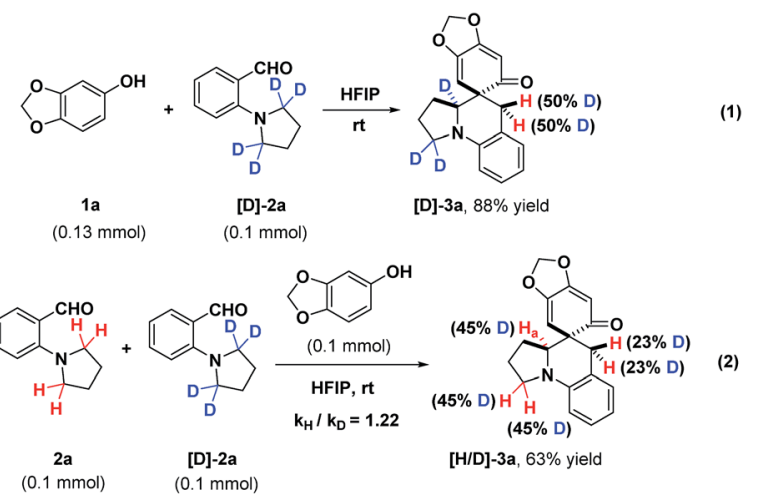

Scheme 7 Deuterium labeling experiments. 


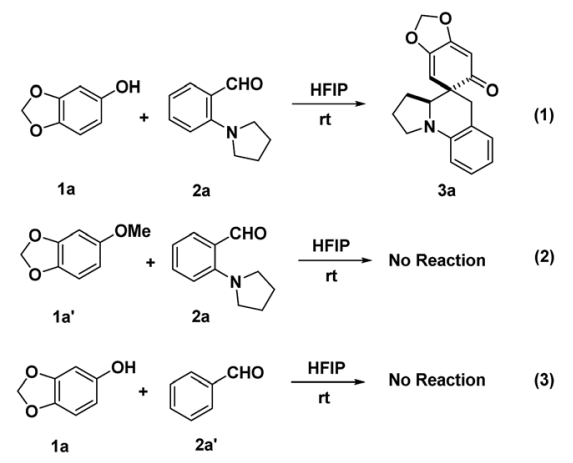

Scheme 8 Control experiments.

not be involved in the rate-determining step (eqn (2)). These results illuminated that the in situ generated $o$-QMs offered a powerful driving force to initiate the intramolecular $[1,5]$-hydride transfer, which was consistent with the fact that this cascade dearomatization/rearomatization/dearomatization proceeded under really mild conditions. Subsequently, some control experiments were conducted to gain more mechanistic insights (Scheme 8). When substrate 1a' containing protected hydroxyl group was subjected to the reaction, no desired product was observed, even under elevated temperature (eqn (2)). This result elucidated the indispensability of the hydrogen bonding interaction between the free hydroxyl group and HFIP in facilitating this reaction. More interestingly, the absence of a hydride donor rendered this reaction unproductive, indicating the significance of hydride transfer in triggering the whole sequential process (eqn (3)).

On the basis of these understandings, a plausible mechanism was proposed as shown in Scheme 9. In view of the fascinating properties of HFIP with strong hydrogen bond donor ability and the cationic species stabilization ability, ${ }^{17}$ we propose that HFIP aggregates reactants 1 and 2 through hydrogen bonding via the double-activation model to generate the nucleophilic addition product A. Assisted by the hydrogenbonding cluster of HFIP, the benzyl alcohol $\mathbf{A}$ undergoes dehydration and dearomatization immediately to furnish $o$-QMs. The propensity of $o$-QMs to rearomatize acts as a powerful driving force to trigger [1,5]-hydride transfer to

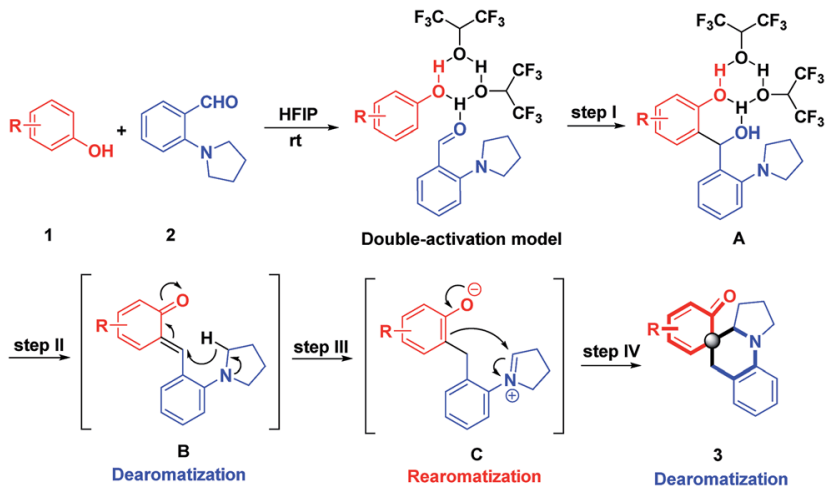

Scheme 9 Plausible reaction mechanism. afford the rearomatic intermediate $\mathbf{C}$, which is followed by nucleophilic dearomatization, generating dearomative cyclohexaketenes as final products. One of the major challenges in this reaction is that three possible reaction pathways might operate: the Friedel-Crafts reaction between phenol and A, $O$-alkylation of intermediate $\mathbf{C}$, and a C-Pictet-Spengler type reaction of intermediate C. Notably, the chemospecificity increases its practical application in medicinal chemistry. In the whole process, the hydrogen bonding network of HFIP plays the key role in generating and stabilizing all the intermediates as well as the well-organized transition states. Recently, combined computational and experimental evidence has revealed that the higher-order aggregates of HFIP are decisive factors to promote the reactions. ${ }^{18}$

\section{Conclusions}

In conclusion, we have developed cascade hydride transfer/ dearomative cyclizations for one-step construction of structurally diverse polycyclic amines in good yields with good functional group compatibilities and high diastereoselectivities. This redox-neutral cascade process addressed several formidable challenges of cascade hydride transfer/cyclization with the following prominent advantages: (1) in situ generated $o$-QMs as novel hydride acceptors and the use of aromatization as the driving force to initiate the hydride transfer without resorting to electron-withdrawing groups; (2) this reaction offers a new reaction mode of $o$-QMs, which were trapped by a hydride and for the first time provides dearomative cyclohexaketenes as final products; (3) a 4-step cascade dearomatization/rearomatization/ dearomatization process with high atom- and step economy for efficient construction of architecturally complex polycyclic amines; (4) mild reaction conditions with operational simplicity, readily available reactants and good functional group tolerance. We are optimistic that this reaction will not only offer synthetic chemists a distinctive toolbox for the generation of diverse polycyclic amine libraries in drug discovery, but also facilitate the one-step assembly of complex molecules via a redox-neutral strategy.

\section{Conflicts of interest}

There are no conflicts to declare.

\section{Acknowledgements}

We are grateful for financial support from the NSFC (No. 21702117, 21878167, U1706210) and the Natural Science Foundation of Shandong Province for Distinguished Young Scholars (JQ201604) and the General Project (ZR2017BB005). Financial support from the Key Research and Development Program of Shandong Province (2017GSF218073) is also gratefully acknowledged. We thank Prof. Xingwei Li (Shanxi Normal University), Prof. Bin Tan (Southern University of Science and Technology) and Prof. Mengchun Ye (Nankai University) for valuable suggestions. 


\section{Notes and references}

1 (a) K. R. Campos, Chem. Soc. Rev., 2007, 36, 1069; (b) O. Baudoin, Chem. Soc. Rev., 2011, 40, 4902; (c) L. Shi and W. Xia, Chem. Soc. Rev., 2012, 41, 7687; (d) E. A. Mitchell, A. Peschiulli, N. Lefevre, L. Meerpoel, B. Maes and U. W. Chem, Chem.-Eur. J., 2012, 18, 10092; (e) C. V. T. Vo and J. W. Bode, J. Org. Chem., 2014, 79, 2809; $(f)$ D. Seidel, Acc. Chem. Res., 2015, 48, 317; (g) S. Mahato and C. K. Jana, Chem. Rec., 2016, 16, 1477.

2 (a) M. Tobisu and N. Chatani, Angew. Chem., Int. Ed., 2006, 45, 1683; (b) B. Peng and N. Maulide, Chem.-Eur. J., 2013, 19, 13274; (c) L. Wang and J. Xiao, Adv. Synth. Catal., 2014, 356, 1137; (d) L. Wang and J. Xiao, Top. Curr. Chem., 2016, 374, 17; (e) L. Wang and J. Xiao, Org. Chem. Front., 2016, 3, 635; (f) S. C. Pan, Beilstein J. Org. Chem., 2012, 8, 1374; $(g)$ M. C. Haibach and D. Seidel, Angew. Chem., Int. Ed., 2014, 53, 5010; (h) M. Xiao, S. Zhu, Y. Shen, L. Wang and J. Xiao, Chin. J. Org. Chem., 2018, 38, 328; (i) S. J. Kwon and D. Y. Kim, Chem. Rec., 2016, 16, 1191.

3 For examples of electrophilic alkenes, see: (a) S. J. Pastine, K. M. McQuaid and D. Sames, J. Am. Chem. Soc., 2005, 127, 12180; (b) S. Murarka, C. Zhang, M. D. Konieczynska and D. Seidel, Org. Lett., 2009, 11, 129; (c) Y. Han, W. Han, X. Hou, X. Zhang and W. Yuan, Org. Lett., 2012, 14, 4054; (d) T. Yoshida and K. Mori, Chem. Commun., 2017, 53, 4319; (e) J. C. Ruble, A. R. Hurd, T. A. Johnson, D. A. Sherry, M. R. Barbachyn, P. L. Toogood, G. L. Bundy, D. R. Graber and G. M. Kamilar, J. Am. Chem. Soc., 2009, 131, 3991; (f) K. Mori, K. Ehara, K. Kurihara and T. Akiyama, J. Am. Chem. Soc., 2011, 133, 6166; $(g)$ C. W. Suh and D. Y. Kim, Org. Lett., 2014, 16, 5374; $(h)$ K. Mori, K. Kurihara, S. Yabe, M. Yamanaka and T. Akiyama, J. Am. Chem. Soc., 2014, 136, 3744; (i) K. Mori, R. Isogai, Y. Kamei, M. Yamanaka and T. Akiyama, J. Am. Chem. Soc., 2018, 140, 6203.

4 For representative examples, see: (a) I. D. Jurberg, B. Peng, E. Woestefeld, M. Wasserloos and N. Maulide, Angew. Chem., Int. Ed., 2012, 51, 1950; (b) D. Chen, Z. Han, Y. He, J. Yu and L.-Z. Gong, Angew. Chem., Int. Ed., 2012, 51, 12307; (c) P. A. Vadola and D. Sames, J. Am. Chem. Soc., 2009, 131, 16525; (d) J. Barluenga, M. Fananas-Mastral, F. Aznar and C. Valdes, Angew. Chem., Int. Ed., 2008, 47, 6594; (e) T. Sugiishi and H. Nakamura, J. Am. Chem. Soc., 2012, 134, 2504; ( $f$ ) C. Theunissen, B. Metayer, N. Henry, G. Compain, J. Marrot, A. Martin-Mingot, S. Thibaudeau and G. Evano, J. Am. Chem. Soc., 2014, 136, 12528; (g) L. Cui, Y. Peng and L. M. Zhang, J. Am. Chem. Soc., 2009, 131, 8394; (h) Y. K. Kang, S. M. Kim and D. Y. Kim, J. Am. Chem. Soc., 2012, 132, 11847.

5 For recently developed hydride acceptors, see: (a) Y.-Z. Chang, M.-L. Li, W.-F. Zhao, X. Wen, H. Sun and Q.-L. Xu, J. Org. Chem., 2015, 80, 9620; (b) C. W. Suh, S. J. Kwon and D. Y. Kim, Org. Lett., 2017, 19, 1334; (c) S. Liu, J. Qu and B. Wang, Chem. Commun., 2018, 54, 7928; (d) S.-S. Li, L. Zhou, L. Wang, H. Zhao, L. Yu and J. Xiao,
Org. Lett., 2018, 20, 138; (e) F. I. M. Idiris, C. E. Majesté, G. B. Craven and C. R. Jones, Chem. Sci., 2018, 9, 2873; For an intermolecular hydride transfer, see: ; $(f)$ W. Chen, L. Ma, A. Paul and D. Seidel, Nat. Chem., 2018, 10, 165.

6 (a) X.-S. Xue, P. Ji, B. Zhou and J.-P. Cheng, Chem. Rev., 2017, 117, 8622; (b) Y. Qin, L. Zhu and S. Luo, Chem. Rev., 2017, 117, 9433.

7 For selected recent reviews, see: (a) W.-J. Bai, J. G. David, Z.-G. Feng, M. G. Weaver, K.-L. Wu and T. R. R. Pettus, Acc. Chem. Res., 2014, 47, 3655; (b) W. Ai, D. Liao and X. Lei, Chin. J. Org. Chem., 2015, 35, 1615; (c) Z. Wang and J. Sun, Synthesis, 2015, 47, 3629; (d) T. P. Pathak and M. S. Sigman, J. Org. Chem., 2011, 76, 9210; (e) N. J. Willis and C. D. Bray, Chem.-Eur. J., 2012, 18, 9160.

8 For the only example of transfer hydrogenation of $o$-QMs, see: Z. Wang, F. Ai, Z. Wang, W. Zhao, G. Zhu, Z. Lin and J. Sun, J. Am. Chem. Soc., 2015, 137, 383.

9 For selected examples, see: (a) J. Izquierdo, A. Orue and K. A. Scheidt, J. Am. Chem. Soc., 2013, 135, 10634; (b) H. Lv, W.-Q. Jia, L.-H. Sun and S. Ye, Angew. Chem., Int. Ed., 2013, 52, 8607; (c) O. El-Sepelgy, S. Haseloff, S. K. Alamsetti and C. Schneider, Angew. Chem., Int. Ed., 2014, 53, 7923; (d) C.-C. Hsiao, H.-H. Liao and M. Rueping, Angew. Chem., Int. Ed., 2014, 53, 13258; (e) J.-J. Zhao, S.-B. Sun, S.-H. He, Q. Wu and F. Shi, Angew. Chem., Int. Ed., 2015, 54, 5460; $(f)$ S. K. Alamsetti, M. Spanka and C. Schneider, Angew. Chem., Int. Ed., 2016, 55, 2392; (g) P. Chen, K. Wang, W. Guo, X. Liu, Y. Liu and C. Li, Angew. Chem., Int. Ed., 2017, 56, 3689; (h) X. Wu, L. Xue, D. Li, S. Jia, J. Ao, J. Deng and H. Yan, Angew. Chem., Int. Ed., 2017, 56, 13722; (i) Y. Xie and B. List, Angew. Chem., Int. Ed., 2017, 56, 4936.

10 S. Zhu, C. Chen, M. Xiao, L. Yu, L. Wang and J. Xiao, Green Chem., 2017, 19, 5653.

11 (a) Q. Zhu, C.-P. Tang, C.-Q. Ke, X.-Q. Li, J. Liu, L.-S. Gan, H.-C. Weiss, E.-R. Gesing and Y. Ye, J. Nat. Prod., 2010, 73, 40; (b) C. Rouger, S. Derbre, B. Charreau, A. Pabois, T. Cauchy, M. Litaudon, K. Awang and P. Richomme, J. Nat. Prod., 2015, 78, 2187.

12 For recent reviews, see: (a) I. Colomer, A. E. R. Chamberlain, M. B. Haughey and T. J. Donohoe, Nat. Rev. Chem., 2017, 1, 88; (b) J. Wencel-Delord and F. Colobert, Org. Chem. Front., 2016, 3, 394.

13 (a) H. Wen, L. Wang, L. Xu, Z. Hao, C.-L. Shao, C.-Y. Wang and J. Xiao, Adv. Synth. Catal., 2015, 357, 4023; (b) J. Liu, L. Wang, X. Wang, L. Xu, Z. Hao and J. Xiao, Org. Biomol. Chem., 2016, 14, 11510.

14 (a) A. R. Pape, K. P. Kaliappan and E. P. Kundig, Chem. Rev., 2000, 100, 2917; (b) W.-T. Wu, L. Zhang and S.-L. You, Chem. Soc. Rev., 2016, 45, 1570.

15 (a) L. L. Anderson, J. Arnold and R. G. Bergman, J. Am. Chem. Soc., 2005, 127, 14542; (b) X. Hu, D. Martin, M. Melaimi and G. Bertrand, J. Am. Chem. Soc., 2014, 136, 13594; (c) J. Zhu, M. Perez, C. B. Caputo and D. W. Stephan, Angew. Chem., Int. Ed., 2016, 55, 1417; (d) M. Amezquita-Valencia and H. Alper, Chem.-Eur. J., 2016, 22, 16774.

16 (a) T. Kimura, J. Hosokawa-Muto, Y. O. Kamatari and K. Kuwata, Bioorg. Med. Chem. Lett., 2011, 21, 1502; (b) 
S. Hosoda, A. Tanatani, K. Wakabayashi, Y. Nakano, H. Miyachi, K. Nagasawa and Y. Hashimoto, Bioorg. Med. Chem. Lett., 2005, 15, 4327.

17 For selected examples of HFIP-promoted reactions, see: $(a)$ M. C. DiPoto, R. P. Hughes and J. Wu, J. Am. Chem. Soc., 2015, 137, 14861; (b) P. A. Champagne, Y. Benhassine, J. Desroches and J.-F. Paquin, Angew. Chem., Int. Ed., 2014, 53, 13835; (c) V. D. Vukovic, E. Richmond, E. Wolf and J. Moran, Angew. Chem., Int. Ed., 2017, 56, 3085; (d) A. M. Mfuh, V. T. Nguyen, B. J. Chhetri, E. Burch, J. D. Doyle, V. N. Nesterov, H. D. Arman and
O. V. Larionov, J. Am. Chem. Soc., 2016, 138, 8408; (e) I. Colomer, C. Batchelor-McAuley, B. Odell, T. J. Donohoe and R. G. Compton, J. Am. Chem. Soc., 2016, 138, 8855; $(f)$ A. Libman, H. Shalit, Y. Vainer, S. Narute, S. Kozuch and D. Pappo, J. Am. Chem. Soc., 2015, 137, 11453; (g) X. Zeng, J. Li, C. K. Ng, G. B. Hammond and B. Xu, Angew. Chem., Int. Ed., 2018, 57, 2924; (h) A. M. Arnold, A. Pöthig, M. Drees and T. Gulder, J. Am. Chem. Soc., 2018, 140, 4344.

18 A. Berkessel, J. A. Adrio, D. Hüttenhain and J. M. Neudörfl, J. Am. Chem. Soc., 2006, 128, 8421. 